\title{
Monism and Pluralism - A Conceptual Analysis of Their Mutual Interactions within Discourses on Religion
}

\author{
Sulagna Pal*
}

\begin{abstract}
This paper examines the questions on how conflicts within and across religious practices could be understood. This paper specifically concerns with the debates around perspectives, both monolithic and plural encountered within the field of religious discourses and at the current juncture provides a way to intervene in the monismpluralism debate in ethics. The various arguments proposed by John Hick, W.T Stace and Keith E. Yandell's pluralistic approach have been analysed for examining the discourses more closely. The aim has been to provide a comparative and critical approach towards monism and pluralism.
\end{abstract}

Keywords: Religious Discourse, Diversity and Monism, Dialectics of Religion

\section{Introduction}

There are a lot of differences in understanding among a common set of people who belong to the same section of the society and have access to similar sources of information and environment. The nurturing environment, in spite of being similar, could lead to disparate views on religion. The locus and origin of the same are hard to discern clearly. However, with time, the perspectives become sharper, and often times, remain locked within

* Department of Philosophy, Janki Devi Memorial College, Delhi, India; sulagnapal8@gmail.com 
encapsulated boundaries. However, in cases, when these individuals engage in a discourse, there arises a situation of conflict: disparate views require negotiation for mutual acknowledgement and intelligibility.

\section{Is Pluralism Tenable?}

In this section, the focus will be on whether pluralism can exist indisputably within the field of human religious expressions and their nuances. Pluralism acknowledges and emphasises on diversity. Acknowledgement of the diversified nature of religious discourses, however, is the first step. As a next step, one has to trace the scope and extent of the identified (religious) diversity. In other words, the one who is analysing the situation has to decide whether the issue has psychological dimensions or has it originated from the human psyche.

John Hick and other philosophers including Ninian Smart, Keith Ward, John Cobb and David Basinger of all have analysed the issue at a deeper level (Hick, 2003). Religious pluralism, in general, holds that no single religion can claim the absolute authority to teach unconditional truth. Religious pluralists point out that nearly all religious texts are nothing more than a blend of human observations documented, for example, as historical narratives, poetry and other normative doctrines. Religious texts are therefore open to interpretations and no religion can systematically capture and communicate all truth. Although all religions attempt to capture reality, their endeavours occur within particular cultural and historical contexts that affect the particular viewpoints (Pluralism, 2015). Religious pluralism is the acknowledgement of significantly diverse and incompatible individual religious beliefs (Basinger, 2015). Hick is one of the major proponents of religious pluralism. Hick says that one requires moving beyond her own position and appreciating the diversity of human contexts. The ground on which this debate is set revolves around certain key issues. The religious pluralists start their journey by encountering the different religious interpretations with a firm belief that there is an existence of genuine interaction between the humans (on one hand) and the transcendent reality on the other. Hick understands the Real in the following way: The Real does not have any fixed 
range of characteristics and is only limitedly experienced by humans. This religious experience of the Real is entirely based upon the concepts borne by the concerned individual mind, although the true nature of the Real always remains beyond anybody's grasp (Hick, 2003).

What remains important however is the fact that the true nature is elusive while the concepts of the individual minds promise of a confirmed belief state. This creates a paradox. The central problem is therefore how one can resolve the conflicts between the diverse interpretations of the Real. Hick shows a way of dealing with this problem. He says that the conflict is an apparent one and is in between the different set of ideas borne by human minds. Moreover, such kind of conflict occurs inevitably owing to the inimitable nature of each individual's diverse religious experience. He says that the individuals have to psychically encounter the complexity of the problem and understand the evident nature of the conflict which they are encountering. The conflict which they are dealing with is nothing over and above a virtual collision of ideas. Such clashes originate from within the partial nature of religious experience. Each religious experience is intensified by a particular aspect of the Real which may be distinctly different from the previous experience.

There are many other scholars who have analysed the nature of religious experiences and have come up with diverse ways of dealing with the issue raised above. One of them is W.T. Stace who has analysed the nature of religious experiences in his paper "The Teachings of the Mystics" (Stace, 1960). Stace has pointed out the fact that the religious experience of individuals A and B who belong to two different cultures is one and the same thing (Stace, 1960). The problem arises when both $A$ and $B$ are asked to describe their individual experience of the omnipresent, unseen power. While narrating their religious experiences, their narrations show the impact of their respective cultures as a result of which $\mathrm{A}^{\prime} \mathrm{s}$ narration of her religious experience remains uniquely different from that of B's. By drawing this distinction, Stace draws a thin line between religious experience and the interpretation of the same. He goes a step ahead and stresses over the fact that pluralism within the field of religion is centred upon the plurality of interpretations 
of one and the same (religious) experience. To elaborate this point further, he argues,

In the theistic religions of the West, in Christianity, Judaism and Islam, the experience of the undifferentiated unity is interpreted as, union with God. But this is an interpretation and is not the experience itself. ...These considerations are further underlined by the fact that quite different interpretations of the same are given in different cultures. (Stace, 2016, p. 512)

It can be inferred from the above lines that Stace is talking about the plurality of religious interpretations (Stace, 2016) while Hick talks about the plurality of religious experiences. Thus, Stace differs from Hick over the point of sameness of religious experience and thus their understanding of religious pluralism is different. Hick was primarily focused on the usefulness of religious activities. For him, it is vital to know whether the religious activity (Hick, 1973), performed by one has any practical worth before looking into any other aspect. He further says that in the present world, the religious side of a human being is one of the many dimensions of life. It should be noted that the members belonging to the same culture may or may not resemble each other in their thought process and from that particular point of diversity, in their ways of thinking, originates pluralism. Further, Hick observes and brings into notice that there has been a gradual displacement of the concept of God by the concept of religion (Hick, 1973). As a result of this displacement, there has been a simultaneous change in the crucial concepts of religion. Now, the question is more about the purposefulness of the religious act performed by any human. Religion is and will always be around us, or it can be said that the humans will always be influenced by religion in one way or the other, but with the change in time, the central questions of religion have changed and will continuously evolve. Thus, it can be said that Hick's thesis on religious pluralism revolves on the axis of the practicality of religious acts which seem to play a key role in his version of religious pluralism.

It can be further said that according to Hick, religion is a way of understanding the world. Humans need to co-exist along with 
their diverse religious beliefs. Due to the need for an appropriate way of co-existence, religious pluralism came into being. Hick seems to discuss the matter of religious pluralism from the point of view of a realist as the entire discussion in a way involves the human community and the real world where they reside. Hick brings into focus some of Wilfred Cantwell Smith's words in order to further strengthen his point. To quote some of Smith's words as put forward by Hick: "In every human community on earth today there exists something, that we, may term a religion" (Hick, 1973). From the above quotation, it becomes evident how Hick visualises plurality in existence of religions in different corners of the earth at one and the same time and in this way conceptualises religious pluralism.

\section{Transcending Hick's Analysis of Religious Pluralism}

Harrison in her paper, "Religious Diversity" (Harrison \& Stewart, 2003), has presented her comments on Hick's religious pluralism. She asserts that Hick's style of acknowledging several religious traditions at one and the same time is highly impressive and has drawn mass attention towards it. However, Harrison finds flaw in Hick's religious pluralistic thesis. She says that, although Hick claims that he has never aimed for a single world religion in a way moving towards monism, there remains a lack of description of the way in which religious pluralism functions within the field of religion where the plurality of religions co-exist, without collapsing into monism. Hick counters this point and says that religions are mythical by nature. In other words, religions exist in the form of myths or have stories of its own to narrate. These myths are considered to be true if and only if they are effective in building up a relationship between the concerned individual and the Real (Harrison \& Stewart, 2003). Critics have commented that his answer is insufficient to understand how the Real is connected.

On the other hand, Yandell in his book, Philosophy of Religion: A Contemporary Introduction, argues against religious pluralism. Yandell does not find the approach of the religious pluralists towards different religious traditions to be quite acceptable. In spite of the popularity gained by pluralism within different domains of human life, religious pluralism seems to be a self-contradictory 
notion in his view (Yandell, 1999). He claims to offer a neutral definition for religion and attempts to capture the world with humans residing within it. Yandell says the following on religion:

... a conceptual system that provides an interpretation of the world and the place of human beings in it, bases an account of how life should be lived given that interpretation, and expresses this interpretation and lifestyle in a set of rituals, institutions, and practices. (Yandell, 1999)

The definition of the term "religion" as described above is a brief description of the functional aspect of it. Besides that, Yandell has also come up with another interesting way of understanding religion (Yandell, 1999). When a man falls sick, he goes onto visit a doctor. The doctor's task is to diagnose the problem which the man is facing and suggest the necessary steps towards its cure. Likewise, people belonging to different religious traditions, who also happen to be members of certain cultures, face regular problems which seem to be solutionless at times. While in search of an answer to all such problems whose solutions seem to exist beyond human reach, humans tend to seek refuge in different religious traditions.

Now, if Yandell intends to draw a link between religion and the human interpretations of the world, then the notion of a plurality of human interpretations arise. Due to the plurality of human interpretations of the same world, there arises the need of applying pluralism as a tool to negotiate these divergent ideas/perspectives. Thus, Yandell's way of unifying all religions into "one" does not really suffice. Instead, one has to reflect on how religious interpretations could be brought into an understanding of intelligible diversity (Yandell, 1999). Another perspective that religion is useful because of its healing values is also important to address. The problems faced by humans may in some way resemble each other and this resemblance, in turn, may act as a common thread between them. Still, the question about the plurality of cures remains open to address. In spite of the fact that Yandell has a critical attitude towards religious pluralism, his own approach seems to come close to Hick's religious pluralistic method. 
Yandell points out that on one hand, Hick calls the Real to be indescribable, while on the other, says that the religious experiences which the humans have are manifestations of the particular mind of the experiencer. The mind of the experiencer, in turn, has concepts which are embedded, pertaining to their membership to a certain culture. Thus, it can be clearly seen that human concepts do have a role to play within the human-Real inter-relationship. So, it cannot be said that the Real is completely indescribable, as one can easily trace out the main ideas related to the Real borne within the minds of individuals belonging to a particular culture and so on. Contrarily, Hick says that the Real which does not have any fixed range of characteristics, is only limitedly experienced by humans and the religious experience of the Real is entirely based on the concepts borne by the concerned individual, although the true nature of the Real always remains beyond anybody's grasp (Hick, 2003). Thus, the restrictions which Hick has forced on religious pluralism are exaggerated. They lead to obvious contradictions in the theoretical premise.

\section{Conclusion}

Hick has been highly criticised for being in support of a universal religious code (implying monism) while remaining within the veil of pluralism. Whether Hick had any real intention of codifying a universal religion or not it is undeniable that his religious pluralistic model shows a tendency towards religious monism rather than pluralism. Yandell too had been using aspects of pluralism within his philosophy, which he apparently claims to be on the lines of monism. However, one of the reasons that lead one to prefer Hick's religious pluralistic approach along with its shortcomings over the other approaches towards religion is due to Hick's way of emphasising the usefulness of religion in the real world where we confront religious problems in our daily lives. Yandell's analysis of religious pluralism is commendable as well but is insufficient for dealing with the complex religious scenario. So it can be very well observed that neither pluralism nor monism can work alone in dealing with complexities irrespective of the field in which they function. 


\section{References}

Basinger, D. (2015). Religious diversity (Pluralism). In E. N. Zalta (ed.), The Stanford Encyclopedia of Philosophy (Summer 2015 Edition).

Harrison, V. S. (2006). The pragmatics of defining religion in a muticultural world. International Journal for Philosophy of Religion, 133-152.

Hick, J. (1973). God and the universe of faiths: essays in the Philosophy of religion. London: Macmillan Press.

Hick, J. (2003). Religious Pluralism. In C. Taliaferro \& P. J. Griffiths (Eds.), Philosophy of religion: An anthology, 124.

Harrison, V. S., \& Stewart, G. T. (2003). Routledge companion to theism: An anthology. Routledge: Blackwell.

Harrison, V. S. (2006). The pragmatics of defining religion in a multicultural world. International Journal for Philosophy of Religion, 59(3), 133152.

Smart, N. (1973). The phenomenon of religion. London and Basing: Macmillan Press Ltd.

Smith, V. S. (1978). The meaning and end of religion: a revolutionary approach to great religious traditions. London: SPCK.

Stace, W. (2003). The Teachings of the Mystics. (In C. Taliaferro \& P. J. Griffiths (Eds.), Philosophy of religion: An anthology, 124.

Yandell, K. E. (1999). Philosophy of religion: A contemporary introduction. London and NYC: Routledge. 